\title{
The gap between what has been defined and what is still pending in occupational health surveillance
}

Luiz Carlos Fadel de Vasconcellos ${ }^{1}$

Carlos Minayo Gomez ${ }^{1}$

Jorge Mesquita Huet Machado ${ }^{2}$

${ }^{1}$ Escola Nacional de Saúde Pública, Fiocruz. R. Leopoldo Bulhões 1480, Manguinhos. 21041-210 Rio de Janeiro RJ Brasil. fadel@ensp.fiocruz

${ }^{2}$ Núcleo de Promoção da Saúde, Ambiente e Trabalho, Diretoria Regional de Brasília, Fiocruz.

\begin{abstract}
The scope of this paper is to address some questions about Occupational Health Surveillance (VISAT) in Brazil based on various elements of analysis, in order to contribute to the debate on this theme at the Fourth National Conference on Occupational Health. The topics discussed in the article are: the role of Reference Centers for Occupational Health (CEREST) as a place for discussing VISAT; training and qualification of the VISAT agents; commitment of workers as subjects of VISAT action; strategies for intersectorial liaison with other areas of the State; and the dialogue between peers working in the field of research and action of VISAT. It should be emphasized that in Brazil there is specific legislation on VISAT that is a priority of the National Labor Policy. The conclusion drawn is that heavy investment in the training of agents and the development of specific guidelines is needed to implement systematic and intersectorial actions in this respect. At the time of the Conference, the greatest expression of the exercise of social control, it is recommended that the participation in surveillance procedures of health workers be evaluated as a precondition to ensure the effectiveness of these actions.

Key words Occupational health, Health surveillance, Occupational health surveillance, Social control in occupational health
\end{abstract}




\section{Introduction}

The need to carry out occupational health surveillance (VISAT) is a question that has been posed since the issue was raised in the Brazilian Constitution of 1988, and particularly during the process by which the area of occupational health has been built up in Brazil. It is a policy which aims to go beyond the simple care dimension which used to prevail (and still prevails to a certain extent) in the early occupational health programs, before the advent of the Unified Health System (SUS) and the forerunners of the Reference Centers for Occupational Health (CEREST).

The main aim of these initiatives was to diagnose and monitor work-related illnesses with a view to creating conditions for turning the public health network into an effective instrument for providing occupational health care, as well as creating certain care programs with regard to accidents at work. With the VISAT program, which is aimed at intervening in those environments, procedures and forms of work organization that can constitute threats to health, a preventive dimension has come to form part of occupational health. In other words, it is only with interventionist surveillance policies that it is possible to break the cycle of illness and death in the workplace. This preventive aspect of healthcare is primarily the responsibility of the National Organization for Occupational Health Care (RENAST), through the CERESTs, which constitute its means for taking effective action.

VISAT is part of the National System for Occupational Health, which aims to promote health and reduce morbidity and mortality rates among the working population, through the integration of action programs with regard to threats and their causes in development models and production processes.

Ministerial Directive No. 1823, of August 2012, which instituted the National Policy for Occupational Health (PNSTT) ${ }^{1}$, states that its primary objective is the strengthening of occupational health surveillance. In accordance with the PNSTT, the Ministry of Health defined it as a priority to strengthen VISAT and to integrate it with other elements of health surveillance, with a view to promoting health, through healthy environments and working procedures. On this basis, the national proposal for strategic action, as set out by the Health Surveillance Department (SVS), was to intensify surveillance programs in the field of occupational health, with the aim of expanding the number of CERESTs involved in these programs, so that by 2015 all of them would be carrying out these activities.

There are a fair number of VISAT texts, which contain detailed material on concepts and methods $^{2-5}$. Some of these texts are concerned with the various modes of VISAT, including dealing with specific threats, including various types of accident, agro-toxic agents, silicosis, asbestosis, benzene, repetitive strain injuries, etc.

It is also possible to observe the results of VISAT in certain sectors of the economy, such as chemicals, petro-chemicals, steel production, cold storage, agro-industry, civil engineering, transport, electrical industries, and health and education, and in certain socio-economic contexts of specific sections of the population, such as child labor, informal and cooperative work, etc.

We also noted that the legal basis for VISAT is to be found in various types of federal, state and municipal legislation, such as for example Organic Health Law 8080 and Ministerial Directive No. 3120 of 1 July $1998^{6}$, at the federal level, and the health constitutions and codes of the various state and municipal entities.

However, in observing VISAT from the point of view of coordinated, articulated and harmonized public action by those bodies that have been attempting to develop such activities, we have seen how much still remains to be done so that we can say that an occupational health system exists in Brazil from this perspective.

Although there have been many initiatives, it is only in a minority of cases that one can speak of a systematic application of VISAT programs, not to mention the fact that in many areas of the country they simply do not exist.

This text, in which the questions and formulations have been synthesized and simplified, contains certain aspects for consideration and discussion at the Fourth National Conference on Occupational Health (CNSTT), which will be held in 2014 in Brasilia, and by all those who in some way have been contributing to the improvement of VISAT in Brazil.

In summary, our discussion is divided into the following topics: (1) the place for considering VISAT - from theory to practice; (2) the training of VISAT agents; (3) the involvement of workers affected by VISAT action; (4) strategies for inter-sectorial links with other areas of government; (5) the dialogue between the parties. 


\section{The place for considering VISAT - from theory to practice}

Occupational health surveillance is understood here in a wide sense as being a public health procedure that involves knowledge and control and intervention practices with regard to the problems that cause injury to health (threats) in the context of working procedures, working environments and the conditions under which work is performed. The purpose of surveillance action is, therefore, to prevent occupational health threats, as manifested by suffering, biological changes, injury, exhaustion, illness, lesions or accidents.

Occupational health surveillance is a characteristic public health program and therefore intimately linked to the Unified Health System (SUS). It is on the basis of SUS that VISAT must be considered. However, as SUS, in its original constitutional conception, is a system that links policies and other structures of the government of Brazil, it is necessary to think in terms of occupational health surveillance as being connected with the other necessary government organizations. This is necessary in order to achieve its primary aim, which is to monitor and intervene in working procedures and environments where there are factors that might prejudice the health of the working population. It is therefore the task of SUS to make these connections, insofar as they are necessary, and to develop programs using its own structural resources where it can do so without the intervention of other entities.

Any consideration of VISAT, within the context of SUS, has an institutional starting point that is legitimized by the rules of SUS, namely RENAST. In turn, RENAST obtains its knowledge of the situation on the round from its operational centers, i.e. the CERESTs. Thus, it is the task of the CERESTs to implement VISAT, whether by disseminating it within SUS itself, where it ought to permeate policy, or outside it. Their role is strategic in this sense, because the CERESTs are not the only operators of VISAT. They represent the basis of technical and legal knowledge, including the training of agents, so that VISAT can be incorporated in the formal structures with powers of intervention. In the case of health surveillance, they can be incorporated with those whose job it is to systematize information, in the case of epidemiological and environmental health surveillance, as well as of those with the power to create demand, basic care, etc.

VISAT may be understood as a complex area of technical considerations and policy, permeat- ed by many conflicting interests. It is intended to support workers in their struggle to obtain healthy conditions, and is not simply a neutral, standardized and purely technical matter ${ }^{7}$. It should be understood as a work in progress that seeks to widen its sphere of influence over health considerations relating to working procedures.

When looking at the whole development of VISAT programs, since the creation of RENAST in 2002, it cannot be said that there is a consolidated VISAT culture in most of the CERESTs. This fact, however, does not take away their privileged position as instigators of VISAT programs. According to the results published in the Second RENAST Report ${ }^{8}$, VISAT programs are being pursued in the majority of CERESTs (58.4\%) and that infrastructure and personnel are adequate, but what is needed is an evaluation of the characteristics of these programs.

There is a tendency by some CERESTs and by various researchers to use the term surveillance programs to cover any activities that are directly or indirectly related to programs to "monitor" health. According to this line of argument, in the broad sense we can say that any program in the field of health is a surveillance program, including those in the strict area of health care. However, our understanding of occupational health surveillance is a program which follows first principles and necessarily results in concrete actions involving intervention in working practices, always with a view to changing practices and carried out with the participation of the workers concerned.

Certain VISAT activities may be carried out by health care professionals, especially those concerned with primary health care. In turn, surveillance teams, including those of VISAT, must organize themselves in order to provide technical back up and support for primary health care networks in situations of medium or high complexity.

Generally speaking, health surveillance finds its parameters in the data that the health system and other systems possess as regards morbidity and mortality rates for the population. Surveillance uses this data as the basis for producing programs and raising public awareness with regard to the need to prevent illnesses and avoid risks. It should be emphasized that the greater the capacity for collecting and analyzing economic, demographic and health data relating to sectors of the population, the greater the possibility that we can build up precise information to assist the process of health surveillance. 
However, for the effective achievement of VISAT programs as we conceive them, it is necessary to redirect the operational focus of the CERESTs, moving from a theoretical statement of intent with regard to VISAT, based on the legislation that promotes or regulates it, to a routine manner of doing things. For this purpose it is necessary to note, within the context of the CERESTs, certain factors which may be conducive towards the realization of VISAT policies, such as: (1) the formation of teams with the capacity to coordinate inter-disciplinary and inter-sectorial programs; (2) the identification of the most problematic situations involving occupational health risks; (3) the preparation of action plans, with the cooperation of workers representatives, for intervention in working procedures or environments; (4) integration with other elements of health surveillance; (5) among other measures, the initiation of administrative and negotiating processes.

Without adopting a more direct and handson approach, VISAT may remain a mere figure of speech, a theoretical formulation of the rules, for most of the CERESTs. In this context, it would be instructive to make a comparative analysis of the current situation of VISAT in Brazil with the results obtained from research entitled "A Study of the Situation and Trends in Occupational Health Surveillance in Brazil"', which was carried out in 2002 at the request of the National Inter-Sectorial Commission on Occupational Health (CIST). The object of this study was to identify Occupational Health Programs (PST) - which in the same year would become part of RENAST - in which there was some experience of VISAT. Among other aspects of these PST, the following elements were examined: complaints that led to interventions; inter-sectorial actions developed; the professional standing of the teams; the procedures and forms of intervention; the impact of actions taken; and the degree of social control in these actions.

The investigation showed various aspects of the situation at that time, such as the fact that the majority of VISAT actions had taken place in the Southeast region, particularly in the state of São Paulo, that trade unions were the greatest instigator of actions, and that inter-sectorial action was more frequent than intra-sectorial action. The difficulties encountered in implementing actions were attributed, among other things, to the lack of qualified teams, financial resources and equipment, the failure to integrate with the various management levels of SUS, and the lack of partnerships with the trade unions.
In the light of these findings, the researchers concluded that the VISAT actions under SUS were simply initial attempts, and that overall performance was weak in the face of the occupational health problems encountered. There has certainly been some progress since 2002, the most obvious being the expansion of actions and the introduction of registers of work-related cases in all the regions and states of Brazil. Actions are being extended nationally, and the areas for action are increasing. However, it would be necessary to undertake a careful analysis of current practice in order to define the extent of this progress.

\section{Intensive training of VISAT agents}

It is generally agreed that there is a need for the training of personnel to operate under the current VISAT rules, bearing in mind the heterogeneous nature of the CERESTs, both as regards managers and technical staff. As well as the training and qualification of technical staff for the CERESTs who can take urgent action to bring about changes, a massive investment in qualifying public and trade union personnel (or other worker representatives) will be necessary. In this way, there will be an expansion in the number of professionals, especially within SUS, who are committed to health surveillance. It will constitute a basic boost for VISAT programs which, as well as ensuring that actions are taken at the local level, will instill in the professional staff involved a public commitment to safeguarding the life and health of the worker. In addition, it will contribute towards a change in the culture of the health sector, as regards the recognition of the area of work as a fundamental social determinant of health.

In the process of training health surveillance agents, it is important to distinguish between the various levels of training, having regard to the technical and technological qualifications of each CEREST in each locality. Obviously, the procedures for health surveillance must be governed by certain methodological criteria established by the rules, especially by the PNSTT, VISAT Directive No. $3120 / 98$ and the VISAT Guidelines ${ }^{10}$, but in some cases they can go beyond these, by seeking new approaches. Given the particular nature of manufacturing and working processes, analyses of risk situations may require the assistance of specialists in various areas of knowledge.

Also part of the process in health surveillance training is the production of manuals, technical rules, intervention technologies, and the moni- 
toring and evaluation of programs, along with instructions containing general and specific guidelines for analyzing work schemes and procedures. What is meant here is documentation that will serve more as a basic operating guide than as a step-by-step prescription or checklist. In this context, there must be a strategic program for training and preparation of materials for the states, bearing in mind health surveillance guidelines and national priorities.

A national program for the training of staff to work in the health surveillance field, following the criteria set out in Ministerial Directive No. 3120 and the PNSTT guidelines, is already being developed. For more details, see the Blog multiplicadoresdevisat.com.

By the term VISAT agents, we mean all the professional staff employed in the CERESTs, including mid-level staff and those who work in the administrative support area, members of CIST and representatives from trade unions. It also encompasses other worker entities in the manufacturing sector that are concerned with local epidemiological factors, and health inspectors who operate under health surveillance programs in the regions covered by the CERESTs. Increasing the qualifications of this group of professionals is a priority, because they are essential to the development of programs. However, it is most important that other agents are trained, particularly professional staff from other disciplines, such as epidemiological and environmental, and professionals from the health care, social security and other sectors, in order to facilitate inter-sectorial and intra-sectorial approaches. Also involved could be public service personnel, such as public prosecutors, university teachers and post-graduate students in the fields covered by VISAT ${ }^{11}$.

It is very important that all training in the VISAT field be directly linked to action. The complexity of the world of work, involving endless production processes of the most varying types, means that priority must be given to those sectors that require the most attention in the various regions of Brazil. Once they have been defined, these sectors should form the specific focus for the training of agents in implementing health surveillance procedures. There are various teaching methods for introducing and sustaining this process over a period of time. For example, programs for the cold storage and agro-toxic industries in certain parts of the south of Brazil have strengthened this method of training/action.

\section{The involvement of workers affected by VISAT action}

It is commonly maintained that campaigns by workers, especially the fight for health, have lost their strength and sense of unity in recent years. The fight for health at work was very important in Brazil in the 1980s and 1990s. Certain cases remain in our memory, such as those relating to leukopenia and benzene, RSI, silicosis, asbestos and many others. All of them succeeded in bringing together the struggle by workers and public action taken by Brazilian public authorities $^{12}$.

According to the RENAST report, the participation of workers in VISAT actions is around $30.7 \%$ of the state CERESTs, and their participation in all actions is $25.5 \%$. As one of the principles of VISAT is worker participation, one would have expected it at around $100 \%$. It is reasonable to agree with the maxim that without the participation of workers there can be no proper worker health surveillance.

Also according to this report, the participation of workers in CIST is something that is still to be evaluated. Although there is a CIST linked to most of the State Health Committees (76\%), there is no evaluation of the frequency or content of meetings, the type of representation or the degree of representative participation. This includes the claims made by the trade unions, and, most of all, the engagement of CISTs in all the stages of VISAT, as required by the concept itself and by the rules. It may also be noted that CISTs, because they are involved in official cases instituted within the context of SUS, have not demanded from the authorities the proper role that is due to them, in particular as regards their responsibility towards those they represent. The efforts of the CISTs that have been seeking this role are still in their infancy. In this regard, it should be noted that:

The Inter-Sectorial Commissions on Occupational Health (Cist) have over recent years been gradually restricted in their scope, because their composition has been structurally unrepresentative and narrow in scope and range. In various states and municipalities, the Cist has become a mere appendage to the health committee, partly because in many places there is a requirement for it to be composed of committee members themselves. Besides being contrary to the spirit behind the creation of the Cists, as regards broadening their inter-sectori- 
al nature, this has also meant that they end up by reproducing the agenda of the health committee ${ }^{13}$.

We could list various reasons for this weakened approach to workers' campaigns, and for the loosening of the bonds between workers and public authorities committed to such campaigns, but this is not the object of this paper. Here we are trying, in a simplified manner, to devise some alternative new approaches to the question of occupational health involving the workers themselves.

At the Third National Conference on Occupational Health, its recommendations insisted on a participative process, consistent with the area involved. The most important points were: (1) extension of the scope of participation in social control to popular movements and rural and informal market worker organizations, as well as to those suffering from work-related illnesses; (2) the creation of consultative management councils and theme committees in health units and Reference Centers for Occupational Health; (3) the organization of wider regional or state forums in order to strengthen the basis of social support; (4) the introduction of training policies for those who participate in the organs of social and health control through serving on the health councils, the management councils and the committees.

In occupational health matters, the trade unions and other organizations representing workers are essential partners in any health surveillance program. They are one of the fundamental elements for the effectiveness and continuity of interventions. For this reason, we insist that in health surveillance processes there is no technical knowledge that can replace knowledge derived from the workers. This knowledge is the fruit of experience and reflection on working practices and must be combined with the knowledge possessed by the experts in any discussion of the problems and the ways to overcome them. In many instances, the knowledge of the workers will be the basis for interventions by health surveillance professionals and for monitoring the actions taken until the problems in question have been resolved.

The greatest guarantee of changes in unsafe working conditions comes when workers show their political strength and proceed to make public demands for changes to the situations that threaten their health. Their presence is essential in defining the priorities resulting from their needs, in the actual activities of preparing and carrying out health inspections, and in the evaluation and continuous monitoring of health surveillance cases and procedures.

On the other hand, it is the task of the CERESTs to reach out to people, in support of the ideals and mission of a public service that is aimed at protecting life and health. Serving the public means taking on the responsibility for pursuing all the alternatives that may be necessary in order to achieve the objective. It is the task of the CERESTs to pursue these aims in a systematic and organic manner following VISAT operational methods. Establishing close ties with the trade union movement and workers' representatives is an essential function for the CERESTs. The way to accomplish this and the strategies to be employed will vary enormously in the light of the social, economic and political conditions at each local level, and it is for the team at each CEREST to establish these.

One of the most interesting experiments in VISAT occurred in the State of Rio de Janeiro between the years 1990 and $1997^{14}$. The Occupational Health Program started by the Rio de Janeiro State Health Department (PST/RJ) set up the State Council for Occupational Health (CONSEST), which included representatives from a number of institutions and from various trade unions. All the actions under the PST/RJ were taken in conjunction with CONSEST. Most of the activities were connected with health surveillance. Workers and unions played an active role, submitting their problems and complaints, planning actions jointly with the experts, taking part in inspections as agents, and evaluating the results of interventions.

CONSEST ended by having representatives from more than fifty categories of workers. For specific actions, technical committees were set up in which workers and experts discussed in detail the problems of health surveillance in their area and prepared the necessary actions before taking to the field. Technical committees were set up for metalworkers, shipbuilding, civil servants, chemical workers, bank workers, data processors, rural workers and other categories.

This collective work also saw the construction of a methodology for operating in the field of occupational health surveillance, especially as regards the participation of trade union representatives as inspection agents. Many actions were initiated and concluded successfully.

Some of the CERESTs recently managed to encourage the training of VISAT agents, as in the case of the few who followed the initiative by the Health Ministry to promote distance-learning 
courses in order to give an impetus to surveillance action in the states ${ }^{15}$. For various reasons, including bureaucratic problems, the initiative did not achieve the success desired.

We are aware that one of the reasons why workers' representatives have become distanced from occupational health structures is the lack of continuity and the low resolution-rate of actions that have been commenced. It is therefore equally important that every action, in every economic/ productive sector, should be capable of producing a resolution rate that can recapture the confidence of workers in public action. For this purpose, it is necessary for evaluative indicators to be produced, showing the aspects that have been resolved and those that still await a solution, in accordance with VISAT principles, and indicators for monitoring the incidence of illnesses in each sector.

Finally, the restoration of confidence between the public services and the public itself (in this case, the workers), will only be achieved to the extent that the continuity of action can be taken over by the working class. This means that the business of surveillance must be the task of the workers, who will notify the public services whenever there are changes in conditions already resolved or which still await a solution. Clearly, the CERESTs and the institutions linked to them must be ready to give a rapid and adequate response to any such notifications.

\section{Strategies for inter-sectorial links with other areas of government}

The inclusion of RENAST and its executive organs within the structure of SUS leads to an institutional attitude that is consistent with the conception, which the health system recognizes and assumes for its functioning. In the case of occupational health, and particularly with regard to VISAT, the degree of complexity involved in the planning of actions requires inter-sectorial links in order to take into account the knowledge requirements for intervention. A complex VISAT action is not viable without bringing to each case the specific knowledge required, to the degree of profundity necessary. In practice, we are only going to find the technical capacity and superior knowledge to analyze and intervene in certain work situations by going to the places where systematized knowledge is produced, namely the universities. Thus VISAT, headed by SUS and working through the CERESTs, depends to a large extent on well-structured links with the universities at every local level. Examples of these fundamental areas for action are to be found in the field of health, but also in engineering, agronomy, economics, law, anthropology and sociology, among other disciplines.

Other links become necessary in the light of the coercive force required to produce changes. Every intervention initiated under VISAT, in whatever economic/productive sector, ends up in a joint negotiation between the State, the trade unions and the employers, where the need for changes in working conditions requires that public authorities should possess coercive powers to ensure the protection of health. Thus, on many occasions, it is necessary to set up joint task forces comprising personnel from various bodies, including Federal and State Public Prosecutor's Offices and Departments of Employment, Social Security, Agriculture, Agrarian Development, Environment, etc. Every productive sector that finds itself subject to the process of health surveillance is liable to need, to the extent of its capacity to confront the authorities, stronger alliances from a political and institutional point of view, in order to make the role of the public sector important in the protection of life and health. It is particularly for this reason that it is important for VISAT programs, operating through the CERESTs, to maintain permanent links with the legislatures (state and municipal), especially their specialist committees (health, human rights, etc.), in order to achieve legal groupings for the protection of workers' health. There are two extremely important activities in this connection: public enquiries and proposals for draft legislation, such as health codes and the specific rules aimed at individual sectors.

The courts are another area for inter-sectorial links, particularly for obtaining a better definition of any question brought before them in problem situations where health surveillance in itself does not have the capacity to intervene in the processes that present risks to health.

\section{The dialogue between the parties}

Many people from different fields of expertise have been studying the problems arising from the work-health relationship. They include personnel from universities, the health network and other executive organs, the legislature, even the courts, and from other civil organizations. Many of these studies are important and could be helping in the adoption of more effective policies towards changing standards relating to 
illness and death at work. However, the bulk of their conclusions are not taken up by the decision makers in the realm of public policy, or by the workers themselves, by lawmakers, by the courts, or by the media. Moreover, research projects financed by pressure groups are not monitored to avoid duplicity in their use of recurrent themes or their contribution towards confronting the problems studied.

In this connection, it is necessary for the themes on VISAT as an object of research to be constructed as a reference point, with the aim of providing assistance for the implementation of health surveillance programs in the sectors studied.

In recent decades, certain initiatives have been taken towards establishing links between researchers and professionals involved in the formulation and introduction of policies in the field of occupational health in Brazil. This is particularly the case with the Occupational Health Working Group (WG) of the Brazilian Association for Public Health (Abrasco), with the realization of the First Brazilian Occupational Health Symposium (SIMBRAST) in 2007, the results of which are to be found in the book $A$ saúde do trabalhador na sociedade brasileira contemporânea ${ }^{16}$. Among other initiatives of the WG in this connection, we should mention the discussions that took place on the guidelines for PNSTT in 2009, with the emphasis on VISAT and on basic care programs, and the publication of the Occupational Health Dossier in two issues of the Revista Brasileira de Saúde Ocupacional in 2013 17,18 .

In the case of projects for the implementation of VISAT related to RENAST, linked action at both the national and regional level could improve its development and lead more quickly to the introduction of rules and techniques for intervention that could be adopted in the other regions of the country. This is the case with the development of projects for specific sectors, such as agriculture, cold storage, civil engineering and transport, among others ${ }^{19}$.

It is feasible to start thinking about strategies for dialogue, financing, monitoring and evaluation of VISAT development projects and research in Brazil, and the time to do it is now.

\section{Final considerations}

It is to be hoped that the government's proposals to implement VISAT programs in all the CERESTs by 2015 will not be frustrated. For this pur- pose, as we have consistently pointed out, it will be necessary to overcome a series of problems of various kinds and to make available the varied set of services in the field of occupational health under SUS, both as regards the make-up of their teams and as regards their levels of action. These are fundamental topics for consideration when defining the priority sectors, programming activities and developing projects with a view to improving the operation of VISAT.

With specific reference to social control, it is surprising to note the large number of state CISTs which exist and the number of representatives from public institutions and organizations of civil society which make up their membership. However, it is right to query the number of those who participate regularly and how frequently meetings are held. Still more, there should be queries as to the subjects debated, particularly as regards complaints and the participation of members in preparing, monitoring and evaluating VISAT activities. At a time of great interest in IV CNSTT - the most significant and far-reaching program for social control - it will be necessary for CISTs, particularly at the national level, to carry out a detailed evaluation of their contribution, with a view to setting targets for the improvement of the work conditions and health of the working population.

The title of this paper, "The gap between what has been defined and what is still pending in occupational health surveillance" has a double significance in recognizing achievement and acknowledging the challenges.

The recognition of achievement goes to those concerned with carrying out occupational health surveillance in Brazil. VISAT requires a lot of effort from these people. The obstacles to the development of VISAT, as well as involving confrontations with economic power, are also present in representative politics and in certain executive agencies of Brazilian public authorities that are charged with the responsibility for the protection of life and health at work. Within the actual structure of SUS, there are enormous difficulties in obtaining support for VISAT, principally on the part of management at various levels and in intra-sectorial sections where there are direct or indirect responsibilities for these matters. Outside the actual health sector, there are also many difficulties in gaining support for VISAT programs, especially with regard to understanding them as a basic priority for public health.

The challenges are to be found in the view that there is a conviction that the protection of 
the lives and health of workers is capable of engaging hearts and minds, especially among those who are undergoing training in the field of occupational health, in order to make the initiatives a reality and rethink the strategies for dealing with the matter.

The health of workers is at the center of the battlefield, and VISAT is the ethical, political, technical and methodological tool for assisting the side that normally loses health, and even life, on this battlefield.

\section{Collaborations}

LCF Vasconcellos, C Minayo Gomez and JMH Machado participated equally in all stages of preparation of the article.

\section{References}

1. Brasil. Ministério da Saúde. Portaria no 1.823 , de 23 de agosto de 2012. Institui a Política Nacional de Saúde do Trabalhador e da Trabalhadora. Diário Oficial da União 2012; 24 ago.

2. Machado JMH. Alternativas e processos de vigilância em Saúde do Trabalhador: a heterogeneidade da intervenção [tese]. Rio de Janeiro: Escola Nacional de Saúde Pública; 1996.

3. Pinheiro TMM. Vigilância em Saúde do Trabalhador no Sistema Único de Saúde: a vigilância do conflito e o conflito da vigilância [tese]. Campinas: Universidade Estadual de Campinas; 1996.

4. Daldon MTB, Lancman S. Vigilância em Saúde do Trabalhador: rumos e incertezas. Rev. bras. saúde ocup. 2013; 38, 127: 92-106.

5. Machado, JMH. A propósito da Vigilância em Saúde do Trabalhador. Cien Saude Colet 2005; 10(4):987-992.

6. Brasil. Ministério da Saúde Portaria GM/MS no 3.120, de $1^{\circ}$ de julho de 1998. Instrução Normativa de Vigilância em Saúde do Trabalhador no SUS. Diário Oficial da União 1998; 2 jul.

7. Pinheiro TMM, Machado JMH, Ribeiro FSN. A vigilância em saúde do trabalhador. In: Conferência Nacional de Saúde do Trabalhador, 3. Brasília: Ministério da Saúde (MS); 2005. Coletânea de textos.

8. Machado JMH. Processo de vigilância em Saúde do Trabalhador. Cad Saude Publica 1997; 13(2):33-45.

9. Brasil Ministério da Saúde (MS). $2^{\circ}$ Inventário da Renast de Saúde do Trabalhador: Acompanhamento da Rede Nacional de Atenção Integral em Saúde do Trabalhador, 2010-2011. Brasília: MS; 2012.

10. Brasil. Ministério da Saúde (MS). Secretaria de Vigilância em Saúde. Diretrizes da Vigilância em Saúde do Trabalhador. Brasília: MS; 2012. 
11. Lacaz FAC, Machado JHM, Porto MFS. Estudo da situação e tendências da vigilância em Saúde do Trabalhador no Brasil. Relatório Final. Rio de Janeiro: Convênio ABRASCO-OPAS; 2002.

12. Vasconcellos LCF, Almeida CVB, Guedes DT. Vigilância em saúde do trabalhador: passos para uma pedagogia. Trab. educ. saúde 2009; 79(3):445-462.

13. Vasconcellos LCF. Saúde, Trabalho e Direito no SUS Por uma agenda de movimentos. In: Bravo MIS, D’Acri V, Martins JB, organizadores. Movimentos Sociais, Saúde e Trabalho. Rio de Janeiro: ENSP; 2010. p. 117-133.

14. Costa KCF. Análise da trajetória do controle social em saúde do trabalhador no Rio de Janeiro [dissertação]. Escola Nacional de Saúde Pública, Fundação Oswaldo Cruz; 2009.

15. Minayo-Gomez C, Vasconcellos LCF, organizadores. Controle social na saúde do trabalhador. Rio de Janeiro: EAD, ENSP; 2009.

16. Minayo-Gomez C, Machado JMH, Pena PGL. Saúde do Trabalhador na sociedade brasileira contemporânea. Rio de Janeiro: Fiocruz; 2011.

17. Dossiê Temático: Atenção integral em saúde do trabalhador: desafios e perspectivas de uma política pública. Rev. bras. saúde ocup. 2013; 37(127).

18. Dossiê Temático: Atenção Integral em Saúde do Trabalhador: Desafios e Perspectivas de uma Política Pública - II. Rev. bras. saúde ocup. 2013; 38(127).

19. Minayo-Gomez C. Produção de conhecimento e intersetorialidade em prol das condições de vida e de saúde dos trabalhadores do setor sucroalcooleiro. Cien Saude Colet 2011; 16(8):3361-3368.

Article submitted on 09/09/2014

Approved 10/09/14

Final version submitted on 11/09/2014 